ERRATUM

\title{
Mechanisms of regulated unconventional protein secretion
}

Walter Nickel \& Catherine Rabouille

Nature Reviews Molecular Cell Biology 10, 148-155 (2009); doi:10.1038/nrm2617

On page 153 of the above article, left column, the wrong figure was cited. The phrase "GrpA could be required for the proper delivery of at least one specific factor to the plasma membrane..." should refer to figure 4, pathway 5 , instead of figure 3 , pathway 5 .

In the reference list, the wrong year was mentioned in reference 4 . The correct reference is as follows:

Nickel, W. \& Seedorf, M. Unconventional mechanisms of protein transport to the cell surface of eukaryotic cells. Annu. Rev. Cell Dev. Biol. 24, 287-308 (2008). 